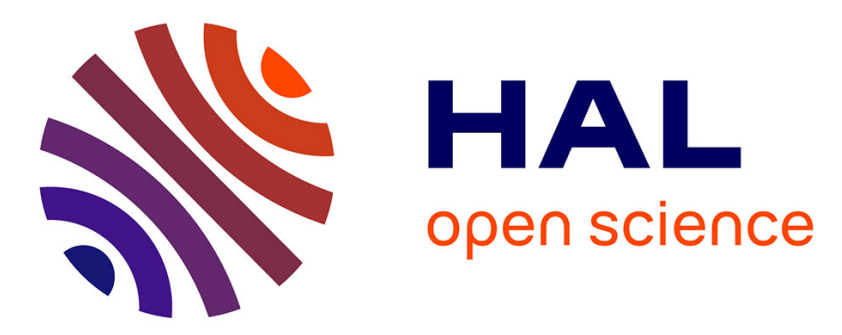

\title{
Breath holding and tidal breathing nasal NO to screen children for Primary Ciliary Dyskinesia
}

Nicole Beydon, Aline Tamalet, Estelle Escudier, Marie Legendre, Guillaume Thouvenin

\section{- To cite this version:}

Nicole Beydon, Aline Tamalet, Estelle Escudier, Marie Legendre, Guillaume Thouvenin. Breath holding and tidal breathing nasal NO to screen children for Primary Ciliary Dyskinesia. Pediatric Pulmonology, 2021, 10.1002/ppul.25432 . hal-03201639

\section{HAL Id: hal-03201639 \\ https: / hal.sorbonne-universite.fr/hal-03201639}

Submitted on 19 Apr 2021

HAL is a multi-disciplinary open access archive for the deposit and dissemination of scientific research documents, whether they are published or not. The documents may come from teaching and research institutions in France or abroad, or from public or private research centers.
L'archive ouverte pluridisciplinaire HAL, est destinée au dépôt et à la diffusion de documents scientifiques de niveau recherche, publiés ou non, émanant des établissements d'enseignement et de recherche français ou étrangers, des laboratoires publics ou privés. 


\section{Breath holding and tidal breathing nasal NO to screen children for Primary Ciliary Dyskinesia}

Nicole Beydon $\mathrm{MD}^{1,2}$, Aline Tamalet $\mathrm{MD}^{3}$, Estelle Escudier MD, $\mathrm{PhD}^{4}$, Marie Legendre PharmD, $\mathrm{PhD}^{4}$, Guillaume Thouvenin $\mathrm{MD}^{2,3}$

${ }^{1}$ APHP, Unité Fonctionnelle de Physiologie-Explorations Fonctionnelles Respiratoires, hôpital Armand-Trousseau, Paris, France

${ }^{2}$ INSERM U934, Centre de Recherche Saint Antoine, Paris, France

${ }^{3}$ AP-HP, Centre de Référence des Maladies Respiratoires Rares, Service de pneumologie pédiatrique, Hôpital Armand-Trousseau, Paris, France

${ }^{4}$ Sorbonne Université, Inserm UMR_S933 Maladies génétiques d'expression pédiatrique, AP-HP Département de Génétique médicale, Hôpital Armand Trousseau, Paris, France

Correspondence to Dr Nicole Beydon, Unité Fonctionnelle de Physiologie-Explorations Fonctionnelles Respiratoires (EFR), Hôpital Armand-Trousseau 26 Avenue du Docteur Arnold Netter, 75571 Paris Cedex 12, France.

Phone : +331447363 32, Fax +33144736336

E-mail nicole.beydon@aphp.fr

Key words: Bronchiectasis \& Primary Ciliary Dyskinesia, Nitric Oxide (NO) Running title: Nasal NO screening in young children 


\begin{abstract}
Nasal Nitric Oxide (nNO) measurement is recommended to screen for Primary Ciliary Dyskinesia (PCD) in subjects with suggestive history and symptoms. Clinical use of alternative methods (ie breath hold $(\mathrm{BH})$, tidal breathing (TB)) in children unable to perform the gold standard slow Exhalation against a Resistance (ER) method has not been sufficiently evaluated.
\end{abstract}

We extracted retrospectively (2013-2019) 454 files (374 subjects) containing nNO results. Median [IQR] age at inclusion was 7.0 [4.7 - 11.0] years, $105(28.1 \%)$ children were younger than 5 years. ER or BH methods were more frequently mastered by children older than 5 years compared to younger children $(69.4 \%$ and $52.7 \%$ versus $21 \%$ and $5.6 \%$, respectively, $P<0.0001$ ), the latter succeeding only in TB measurement in $77.4 \%$ of cases. In 130 files with both ER and $\mathrm{BH}$ measurements (nNO-ER and nNO-BH), nNO-BH was $102[96.2 ; 108.3] \%$ that of nNO-ER. In 175 files including nNO-ER and nNO-TB measurements, nNO-TB was 64.4 [IQR: 53.7;80.4]\% that of nNO-ER with an excellent correlation between $\mathrm{nNO}$ values $(\mathrm{r}=0.94$ [95\%CI 0.91;0.95]; $P<0.0001)$ and discordance in the interpretation of $\mathrm{nNO}$ results in $16(10.2 \%)$ cases.

Final PCD diagnosis was similar in patients included before or after 5 years of age (confirmed $16(15.2 \%)$ and 48 (17.8\%); excluded 81 (77.1\%) and $192(71.4 \%)$, respectively; $P=0.32$ ).

In conclusion, reliable $\mathrm{nNO}-\mathrm{BH}$ and $\mathrm{nNO}-\mathrm{ER}$ results are interchangeable. Children tested with ER or with TB method have similar final PCD diagnosis. Alternative methods to measure nNO might be studied further for use in clinical practice. 


\section{Introduction}

Primary Ciliary Dyskinesia (PCD) is a congenital disease that causes early onset of respiratory symptoms, contrasting with a usually delayed diagnosis. In the absence of a simple and unique gold standard test for diagnosing PCD in patients with suggestive clinical symptoms, European and North American working groups recommend first to exclude any differential diagnosis, then to perform nasal Nitric Oxide (nNO) measurement along with other tests such as high-speed video microscopy, ciliary ultrastructure or genetic analyses $^{1-3}$.

It is now well established that patients with Cystic Fibrosis or PCD have very low nNO output, though the reason for this remains elusive, especially since few PCD patients with specific mutations have a normal level of $\mathrm{nNO}^{4}$. However, the measurement of $\mathrm{nNO}$ remains the easiest technique to screen the majority of PCD patients.

In order to decrease the age at diagnosis, it is necessary to gather evidence on the feasibility, reliability and clinical utility of nNO obtained in younger children, especially when the gold standard method (slow exhalation against a resistance (ER)) for $\mathrm{nNO}$ measurement is difficult to obtain or to interpret.

False positive nNO results (low nNO value in children without PCD), the most problematic outcome, are frequently ascribed to obstructive rhinitis, which should be detected by examining the child's nose before measurement ${ }^{5}$. They can also be suspected in the presence of irregular NO traces, therefore it is necessary to repeatedly check any low nNO value ${ }^{5}$. Another cause for false positive $\mathrm{nNO}$ tests in young children could be the use of an inadequate (too high) threshold to discriminate PCD from non-PCD children. Airway NO production is maximal in paranasal sinuses ${ }^{6}$ and increases along with paranasal sinuses 
development during the first decade, reaching adult values thereafter ${ }^{7}$. As a consequence, thresholds of nNO established in subjects over 12 years of age may not be suitable for young children with physiologically lower NO output ${ }^{8}$. Moreover, thresholds established for methods involving velum closure (ER or breath hold $(\mathrm{BH})$ ) are higher than those computed using the tidal breathing (TB) method, the latter often being the only method available in young children ${ }^{9-11}$. Finally, alternatives to the gold standard ER method (ie $\mathrm{BH}$ and TB methods) have been used in children, with excellent sensitivity and specificity 13-18. However, the proportion of children able to master BH or TB but not ER method, along with the clinical usefulness of these alternative methods, have not been evaluated in routine practice.

In order to describe the use in routine practice and the potential clinical impact of $\mathrm{nNO}$ measured using $\mathrm{BH}$ or $\mathrm{TB}$ methods (nNO-BH and $\mathrm{nNO}-\mathrm{TB}$, respectively) in young children, we set up a retrospective study on a large population screened for PCD.

\section{Subjects and methods}

We retrieved retrospectively (2013 to 2019) all files containing nNO results from the database of a pulmonary function test department located in a tertiary hospital. Since that hospital is a national reference center for PCD diagnosis, children are sent from all over the country for a work-up. Families were informed of the possible retrospective use of their children's results (declared to the French authority for data protection, CNIL) and gave oral consent. The database contains all routine $\mathrm{nNO}$ tests results deemed technically reliable and could include one, two or three results per file, according to the methods used 
(ER and/or $\mathrm{BH}$ and/or TB). We recorded other tests performed as part of the patients' diagnosis work-up and we noted the final diagnosis.

\section{Material}

NO was measured online using a chemiluminescence NO analyzer (NIOX Flex, Aerocrine Solna, Sweden, in 2013 and 2014, then CLD 88sp NO-analyzer, Eco Medics AG, Duernten, Switzerland from 2015 to 2019 , with a flow rate sample of $0.3 \mathrm{~L} . \mathrm{min}^{-1}$ and 0.33 L.min ${ }^{-1}$, respectively). Real-time NO curve was displayed on the screen. Ambient NO was recorded before each test.

\section{Exhaled NO measurement}

Before $\mathrm{nNO}$ measurement, children over 3 years tried to perform an online measurement of exhaled NO (eNO) at a $50 \mathrm{~mL} \cdot \mathrm{s}^{-1}$ expiratory flow (bronchial eNO) in order to assess their chance of success with the ER method, as that method requires a similar respiratory maneuver (Figure E1).

\section{Nasal NO measurements}

Transnasal nNO measurements were performed as previously described ${ }^{18}$ in a seated child (sometimes in a lying sleeping infant) with an olive inserted in one nostril entraining air from the other nostril. Subjects were constantly exhaling (through the machine circuit or through a party blower) against a resistance of 8 to $10 \mathrm{cmH}_{2} \mathrm{O}$ (ER method) or breath holding (BH method) at Total Lung Capacity during a Valsalva maneuver to achieve velum closure until an NO plateau was reached (maximum - minimum NO values within $10 \%$ of the mean). $\mathrm{nNO}$ value was the mean of an at least $3 \mathrm{~s}$ duration plateau. During tidal breathing (TB method), subjects breathed regularly, with mouth closed for most of them, which determined a succession of variations in the NO concentration on the trace. 
Measurements during crying were not reported whereas measurements during sleep were recorded when the breathing pattern was regular (peaks within 10\%). The mean of 5 peaks during regular breathing was recorded. Measurements were performed in both nostrils and the mean value was reported, except when the difference between the two nostrils exceeded $10 \%$ and then the highest value was recorded.

It is to be noted that some early files (2013-2104) were part of a previous prospective study ${ }^{18}$ during which we performed TB method in all patients. After this study, we set up a Standard Of Procedure (SOP) according to which children less than 8 years of age always performed a nNO-TB measurement first while older patients were first tested with nNOER or nNO-BH methods (Figure E1). (See online Supplemental Material)

When $\mathrm{nNO}$ measure was low or performed with a high ambient NO, we proposed to control the measure, but a second visit often could not be arranged for children who lived far. Moreover, our dataset did not include visits that did not yield results (eg non-cooperative children or obvious and total nasal obstruction).

\section{Final diagnosis}

The final diagnosis was established according to the ERS recommendations ${ }^{1}$, or after discussing the case with a multidisciplinary panel of experts attended by a clinician, a beat ciliary microscopist, a TEM microscopist, a physiologist, and a geneticist ${ }^{19}$. Among the 63 PCD children, 40 children had typical cilia ultrastructure defects, of which 35 also had bi-allelic pathogenic mutations in PCD genes (4 genetics results still pending), and 19 had a pathogenic genotype without abnormal cilia ultrastructure. In addition, three children with Kartagener Syndrome and low nNO (one with immotile cilia), and one child with 
typical clinical presentation, low nNO and immotile cilia were considered as PCD by the panel.

\section{Statistical analysis}

The nNO thresholds used throughout the study period to take medical decision were those previously established for children 4 years and older (ie $82 \mathrm{~nL} \cdot \mathrm{min}^{-1}$ for nNO-ER and nNOBH methods, and $40 \mathrm{~nL} \cdot \mathrm{min}^{-1}$ for $\left.\mathrm{nNO}-\mathrm{TB}\right){ }^{18}$. In children younger than 4 years (73 results in 61 children), the threshold used for nNO-TB was the lower limit of normal published by Adams and colleagues from birth up to 1 year (9 files in 8 infants) ${ }^{10}$, progressively increased between 1 year and 4 years to smoothly fill the gap between $34 \mathrm{~nL} \cdot \mathrm{min}^{-1}$ and 40 nL. $\min ^{-1}($ Table E1).

Results were described as number (percentage), or median [Q1;Q3] (range). Proportions were compared using the Chi-2 test. Comparisons between paired and unpaired data were performed using the Wilcoxon matched-pairs rank test or the Mann-Whithney test, as appropriate. Correlation between nNO-ER and nNO-TB was established using the Spearman's test. We performed Bland and Altman plots to investigate the inter-method agreement. Receiver Operating Characteristic (ROC) curves were constructed to look for the best nNO threshold (Youden test) in specific age groups. Statistics were performed using GraphPad Prism (version 6.01). $P$ value $<0.05$ was considered as significant.

\section{Results}

We retrieved 454 files belonging to 374 children or young adults with a median [Q1;Q3] (range) age of $7.0[4.7 ; 11.0](0.3-19.4)$ years at inclusion, including $105(28.1 \%)$ children 
aged less than 5 years at the time of measurement (Figure 1). The files were evenly distributed across years, except for 2014 when we changed NO analyzer (Figure E2). Among the 412 tests performed in 336 patients 3 years or older, 262 (63.6\%) tests included a bronchial eNO result. Children who succeeded at this measurement were significantly older $(9.9[7.0 ; 12.9]$ versus $7.4[4.2 ; 6.7]$ years; $P<0.0001)$ and succeeded more frequently at ER method than children who failed bronchial eNO manoeuver (208 (79.4\%) versus 44 (29.3\%); $P<0.0001)$. (see Online Supplementary Material)

The dataset included $255 \mathrm{nNO}-\mathrm{ER}, 181 \mathrm{nNO}-\mathrm{BH}$ and $361 \mathrm{nNO}-\mathrm{TB}$ measurements (Figure 2). There was more than one visit in 57 (15.2\%) children, of whom 41 (71.9\%) had two visits during which they performed one, two or three methods each time (26, 13 and 44 duplicate results for ER, BH and TB methods, respectively (see Online Supplementary Material). The proportion of patients with repeated measures was similar between those under and over 5 years at the time of inclusion ( $20 \%$ versus $13.4 \%, P=0.15)$. (see Online Supplementary Material)

The number of measurements according to age and methods performed is given in Table 1. As a consequence of the SOP we used (Figure E1), not all between-group comparisons were relevant. There was a significantly larger proportion of patients over 5 years able to master ER (69.4\%) or BH (52.7\%) method compared to children younger than 5 years (21.0\% and 5.6\%, respectively; $P<0.0001$ for both methods), and a larger proportion of patients aged less than 5 years ending up with only a nNO-TB result compared to older patients $(77.4 \%$ versus $15.7 \%, P<0.0001)$. The age distribution of patients able to perform the BH method but not ER, or only the TB method is shown in Figure 3. 
At inclusion, nNO-TB, nNO-BH and nNO-ER were measured higher than the discriminant threshold in 202/295 (68.5\%), 101/150 (67.3\%) and 140/207 (67.3\%) patients, respectively $(P=0.95)$. In 130 files including both $\mathrm{nNO}-\mathrm{ER}$ and nNO-BH results, the value of nNOBH was 102 [IQR: 96.2;108.3]\% that of nNO-ER without significant difference between the two nNO values $(P=0.08)$ (Figure 4a). In four $(3.1 \%)$ of these files, the interpretation of the result according to the threshold was discordant between nNO-ER and nNO-BH. In 175 tests that yielded nNO-ER and nNO-TB results, the value of nNO-TB was 64.4 [IQR: $53.7 ; 80.4] \%$ that of $\mathrm{nNO}-\mathrm{ER}$ with an excellent correlation between $\mathrm{nNO}$ values $(\mathrm{r}=0.94$ [95\%CI $0.91 ; 0.95] ; P<0.0001)$ (Figure 4b). In 19 tests $(10.9 \%)$ the nNO-TB value was higher than the nNO-ER value, in favor of an unreliable nNO-ER measurement or of an undetected significant nasal obstruction. Apart from these 19 unreliable tests including two discordant results, there were $16(10.2 \%)$ cases of discordance in the interpretation of nNOER and nNO-TB.

Between patients younger and older than 5 years at inclusion, the diagnosis of PCD was equally confirmed $(15(14.3 \%)$ versus $48(17.8 \%)$, respectively; $P=0.50)$ or excluded (82 (78.1\%) versus $192(71.4 \%)$, respectively; $P=0.23$ ) (Table 2). Ciliary beating analysis and genetics studies were performed in similar proportions in these two groups of patients (58 $(55.2 \%)$ versus $174(64.7 \%)$ for cilia beats, $P=0.12$, and $19(18.3 \%)$ versus $63(23.5 \%)$ for genetics studies, $\mathrm{P}=0.34$, respectively) whereas respiratory biopsies for ciliary ultrastructure analysis were more frequently performed in patients over 5 years $(P=$ 0.0002) (Table 2). Results on final work-up according to nNO methods successfully performed in children younger than 5 years of age are given in Table E3. 
ROC analyses were performed using a maximum of one result per method for each patient. In patients 5 years or older, sensitivity and specificity of nNO measurement to discriminate PCD disease were 84.6 (95\%CI 73.3; 95.9)\% and 92.4 (95\%CI 87.9; 96.9)\%, respectively, for $\mathrm{nNO}-\mathrm{ER}(\mathrm{n}=171)$, and $86.1(95 \%$ CI $74.8 ; 97.4) \%$ and $87.9(95 \% \mathrm{CI} 81.4 ; 94.3) \%$, ), respectively, for $\mathrm{nNO}-\mathrm{BH}(\mathrm{n}=135)$. In children under 5 years $(\mathrm{n}=90)$, nNO-TB sensitivity and specificity were $76.9(95 \% \mathrm{CI} 54.0 ; 99.8) \%$ and 85.7 (95\%CI $77.9 ; 93.5) \%$, respectively. The low sensitivity of the TB method was explained by three false negative tests (values higher than the threshold in PCD children) in two children with RSPH1 or CCDC103 mutation, and in a child with Kartagener syndrome and pending genetic results (see Online Supplementary Material). In 230 children (47/230 PCD) younger than 12 years, the ROC analysis of nNO-TB results did not show a different threshold from what we previously established ${ }^{18}$ and used in this study (Table E2, see Online Supplementary Material).

Median [Q1;Q3](range) of ambient NO (NOamb) measured before 449 (99\%) tests was $6.4[1.9 ; 19](0-126) \mathrm{ppb}$ (Figure E2). Correcting for NOamb by subtracting it to $\mathrm{nNO}$ measures would have changed the interpretation of $\mathrm{nNO}$ in $16(3.6 \%)$ tests performed in 15 children (Table E3). (see Online Supplementary Material)

\section{Discussion}

In this retrospective study including $454 \mathrm{nNO}$ measurements performed in 374 children and young adults suspected of PCD, the TB method was the only method feasible in $77.4 \%$ of children younger than 5 years, of whom $21 \%$ could perform the gold standard ER method. Conversely, the BH method succeeded in only $14.8 \%$ of the patients 5 years or 
older unable to perform ER method, but the results of these two methods proved interchangeable. Frequencies of corroborative tests undertaken and final diagnoses were similar between the patients included before and after 5 years, except for TEM, which was more frequently undertaken in older patients.

Because nNO measurement is a simple, highly sensitive and specific noninvasive test to screen children for PCD, it is recommended by the American Thoracic Society (ATS) and by the European Respiratory Society (ERS) ${ }^{1,3}$. However, measuring nNO early in life cannot always rely on the gold standard ER method because the younger the child is, the more frequently he or she would fail at this method (before 5 years for ATS, and before 6 years for ERS). In this context, the feasibility and clinical usefulness of alternative methods to assess $\mathrm{nNO}$ in routine practice should be considered. Adding to the difficulty of interpreting $\mathrm{nNO}$ values, $\mathrm{nNO}$ production in healthy children increases from birth up to 12 years of age (along with the development of nasal sinus) before leveling off 6,7,10,11,20. nNOTB increases quickly from very low values in the first month of life $(17.7$ [95\%CI: 8.8;35.6] ${ }^{10}$ and 15 [IQR: $\left.\left.9.6 ; 22.8\right]^{11} \mathrm{~nL} \cdot \mathrm{min}^{-1}\right)$ to four time this value at 1 year $(56.4$ [IQR: $36.3 ; 75.2]$ ${ }^{10}$ and 69.4 [95\%CI: 34.0;142.0] ${ }^{11}$ nL.min ${ }^{-1}$ ); it then less than doubles during the second year of life (95.4 [IQR: 67.0;128.4] nL. $\mathrm{min}^{-1}$ at 2 years $\left.{ }^{10}\right)$. These low initial values with large inter-individual variability might be impacted by any change in nasal flow or in NOamb, complicating the discrimination of PCD in infancy, as we found.

The BH method has been used in children and in adults with a 100\% feasibility ${ }^{13-17,21-24}$, but it is less adapted in young children: only $2(3.2 \%)$ out of 62 preschoolers (4.1 to 6 years) and $43(14.7 \%)$ out of 293 healthy children (3 to 7.2 years) were able to complete it ${ }^{8,25}$ (see Online Supplemental Material). Therefore, the advantage of BH method would be 
to offer an alternative method for school-aged or older patients unable to perform nNOER. nNO-BH has frequently been found higher or close to nNO-ER in studies which compared both measures in healthy or sick subjects (eg in healthy adults or children nNO$\mathrm{BH}$ versus nNO-ER were, respectively, 201.3 versus 228.9 nL.min ${ }^{-1}(P=0.1)^{24} ; 272.4$ versus $236.4 \mathrm{~nL} \cdot \mathrm{min}^{-1}$ (mean difference $\left.3.5 \pm 53.5\right)^{8}$; 366.5 versus $393.7 \mathrm{~nL} \cdot \mathrm{min}^{-1}{ }^{17}$; and 90.1 versus 8.9 nL.min ${ }^{-1}{ }^{23}$ ). To ensure velum closure during $\mathrm{BH}$, it is proposed to concomitantly measure nasal $\mathrm{CO}_{2}{ }^{12}$, but this technique is not available in all settings. Theoretically, there should be no difference between nNO values obtained with any method involving velum closure and no superimposed nasal airflow (no humming), while in case of communication between the nose and the pharynx a lack of plateau achievement or a plateau with low level of nNO should be seen. Any nNO-BH result that is low or around the threshold could be confirmed by a nNO-TB measurement (Figure E1), whose result is expected to be around half to two thirds that of nNO-BH ${ }^{26}$. By contrast, high above the threshold nNO-BH results without technical issue (low ambient NO) could be considered as reliable as nNO-ER results and of clinical usefulness.

Regarding the TB method, we confirmed: i) the high success rate in children younger than 5 years $\left(95.2 \%{ }^{8}\right.$, present study $\left.97.6 \%\right)$, while a minority of these children could achieve nNO-ER measurement; ii) the excellent correlation between nNO-TB and nNO-ER results obtained in same patients; iii) the good concordance with ER method in terms of interpretation of the results. Our point was to assess whether nNO measurements performed before the age of 5 (mostly using the TB method) would result in a similar work-up for PCD diagnosis, which it did, except for TEM. We probably performed respiratory biopsy less frequently in the youngest because of the difficulty to obtain a correct sample before 
10 years of age ${ }^{27}$. Respiratory biopsy is an invasive procedure which cannot be repeated too often, especially in young children for whom we may have reasoned differently (more observation times, genetic analysis performed earlier).

Sensitivity and specificity were similar across the three methods used to measure nNO, but slightly lower than that reported in a meta-analysis of 13 prospective studies (sensitivity $0.95(95 \%$ CI $0.91-0.97)$, specificity $0.94(95 \%$ CI $0.88-0.97))^{28}$. As previously explained, we could not check all low nNO results: some of them were probably false positive results due to mild nasal obstruction, while some false negative TB tests could be ascribed to specific mutations in PCD children, or to high ambient NO in some cases.

The issue of high level of ambient NO during $\mathrm{nNO}$ measurements has received little attention so far. In healthy children, it has been evaluated that ambient NO accounts for half of its value in nNO-BH result ${ }^{7}$. In another multicenter study, the impact of ambient NO was found to be non-significant in the town with persistently low ambient NO level (5.0 $[95 \%$ CI 14.0 to 28.4$] \% ; P=0.63)$. In opposite, in the two towns where ambient NO could reach $100 \mathrm{ppb}$, ambient NO significantly impacted nNO, but with a large variability, $(24.2[95 \% \text { CI } 4.9 \text { to } 47.0] \% ; P=0.015 \text {, and } 19.8[95 \% \text { CI } 7.7 \text { to } 33.3] \% ; P=0.001)^{29}$. Recommendations are to provide $\mathrm{NO}$-free air for $\mathrm{nNO}$ measurement, or to record the ambient NO for each test in order to take it into account ${ }^{12}$. But no study has evaluated settings aimed at providing NO-free air during nNO measurement in children, and there are no consensual guidelines on how to take ambient NO into account in children. In adult subjects, it is proposed to subtract $100 \%$ of ambient NO to the measurement ${ }^{30}$. From our results, we can state that $\mathrm{ER}$ and $\mathrm{BH}$ methods are less impacted by ambient NO than TB method. Therefore, ambient NO will influence nNO interpretation in the youngest with 
physiological low nNO level and often only nNO-TB result. It can also influence the interpretation of $\mathrm{nNO}$ in all subjects with borderline values measured in settings where ambient NO is high.

Our study has several limitations. First, we did not intend to rate the real feasibility of different methods to measure $\mathrm{nNO}$ in children, which would have required the inclusion of all attempts of nNO measurement without result available. The feasibility of different methods has already been published ${ }^{8,13-17,21-25}$, and we focused on which methods were successful according to the patient's age and on the relationships between methods used and work-up or final diagnosis. Second, the thresholds we routinely used during the study were higher than those proposed by international guidelines (eg 82 versus $77 \mathrm{~nL} . \mathrm{min}^{-1}$ for ER method), which were not available at the beginning of the study. Instead, throughout the study we used the thresholds previously validated in our center ${ }^{18}$. As our aim was to retrospectively assess the clinical usefulness of $\mathrm{nNO}$ results interpreted as we did at the time of measurement, it would not have been relevant to show our results according to different thresholds. Lastly, we were not able to assess to what extent the work-up had truly been influenced by nNO result because we could not track the exact order of the tests. However, the proportion of children with nNO results higher or lower than the discriminant threshold was similar across the three methods evaluated, as well as among children with PCD diagnosis confirmed or excluded, independently of the patient's age. Moreover, there were no differences in PCD diagnosis or in frequencies of corroborative tests performed according to patients' age (except for TEM) (Table 2) or nNO methods used (Table E3). Our results are in favor of mastering all methods available to measure nNO in children. It is probable that the youngest will not be able to perform the gold standard nNO-ER, whose 
threshold might not be adapted to their age, and that some older children will fail the ER method. The inability to perform a bronchial eNO measurement could help indicate which patients will require alternative methods for nNO measurement. In this case, a correct nNOBH measurement, especially when corroborated by the nNO-TB result, could be considered as usable in clinical practice. In settings without resources for ciliary beat analysis, $\mathrm{nNO}$ measurement might be of utmost importance to guide the work-up, especially in the youngest in whom respiratory biopsies are less frequently successful.

Standardization of alternative methods to measure $\mathrm{nNO}$ along with the procedure to take into account ambient NO are currently lacking. The present evaluation of the clinical usefulness of these methods in routine practice should raise interest in developing such guidelines.

\section{Acknowledgments}

We are grateful to Jessica Assouline, Michèle Boulé, Houda Guillo, Marc Koskas, MarieClaude La Rocca, Fatama Lacin, Lucia Maingot, and Noria Medjahdi for their help in supervising the children's lung function tests, and to Claire Goaguen, Pascale Jacquemart, Fanny Koëth, Valérie Le Bail, Hélène Morsył̣, Isabelle Schmit, and Françoise Vallée for technical assistance, all working in Unité d'Exploration Fonctionnelle Respiratoire, Hôpital Armand-Trousseau, Paris, France. We are grateful to Chancellerie des Universités de Paris (Legs Poix grant) for their support to the genetic activity of our center. We thank Camille Beydon for her linguistic advices.

Financial/nonfinancial disclosures: The study received no funding 


\section{References}

1. Lucas JS, Barbato A, Collins SA, Goutaki M, Behan L, Caudri D, Dell S, Eber E, Escudier E, Hirst RA, et al. European Respiratory Society guidelines for the diagnosis of primary ciliary dyskinesia. Eur Respir J.2017;49: 1601090 doi.org/10.1183/13993003.01090-2016.

2. Shapiro AJ, Davis SD, Polineni D, Manion M, Rosenfeld M, Dell SD, Chilvers MA, Ferkol TW, Zariwala MA, Sagel SD, et al. Diagnosis of Primary Ciliary Dyskinesia. An Official American Thoracic Society Clinical Practice Guideline. Am J Respir Crit Care Med. 2018;197:e24-e39.

3. Shapiro AJ, Davis SD, Leigh MW, Knowles MR, Lavergne V, Ferkol T. Limitations of Nasal Nitric Oxide Testing in Primary Ciliary Dyskinesia: Comment on "Diagnosis of Primary Ciliary Dyskinesia. An Official American Thoracic Society Clinical Practice Guideline.” Am J Respir Crit Care Med. 2020; doi:10.1164/rccm.202003-0835LE.

4. Knowles MR, Ostrowski LE, Leigh MW, Sears PR, Davis SD, Wolf WE, Hazucha MJ, Carson JL, Olivier KN, Sagel SD, et al. Mutations in RSPH1 cause primary ciliary dyskinesia with a unique clinical and ciliary phenotype. Am J Respir Crit Care Med. 2014;189:707-717.

5. Shapiro AJ, Dell SD, Gaston B, O’Connor M, Marozkina N, Manion M, Hazucha MJ, Leigh MW. Nasal Nitric Oxide Measurement in Primary Ciliary Dyskinesia: A Technical Paper on Standardized Testing Protocols. Ann Am Thorac Soc. 2019; doi:10.1513/AnnalsATS.201904-347OT. 
6. Lundberg JO, Farkas-Szallasi T, Weitzberg E, Rinder J, Lidholm J, Anggåard A, Hökfelt T, Lundberg JM, Alving K. High nitric oxide production in human paranasal sinuses. Nat Med. 1995;1:370-373.

7. Struben VMD, Wieringa MH, Mantingh CJ, Bommeljé C, Don M, Feenstra L, de Jongste JC. Nasal NO: normal values in children age 6 through to 17 years. Eur Respir J. 2005;26:453-457.

8. Marthin JK, Nielsen KG. Choice of nasal nitric oxide technique as first-line test for primary ciliary dyskinesia. Eur Respir J. 2011;37:559-565.

9. Stehling F, Roll C, Ratjen F, Grasemann H. Nasal nitric oxide to diagnose primary ciliary dyskinesia in newborns. Arch Dis Child Fetal Neonatal Ed. 2006;91:F233.

10. Adams PS, Tian X, Zahid M, Khalifa O, Leatherbury L, Lo CW. Establishing normative nasal nitric oxide values in infants. Respir Med. 2015;109:1126-1130.

11. Marthin JK, Philipsen MC, Rosthoj S, Nielsen KG. Infant nasal nitric oxide over time: natural evolution and impact of respiratory tract infection. Eur Respir J. 2018;51: 1702503. doi: 10.1183/13993003.02503-2017.

12. ATS / ERS. Recommendations for Standardized Procedures for the Online and Offline Measurement of Exhaled Lower Respiratory Nitric Oxide and Nasal Nitric Oxide, 2005. Am J Respir Crit Care Med. 2005;171:912-930.

13. Karadag B, James AJ, Gültekin E, Wilson NM, Bush A. Nasal and lower airway level of nitric oxide in children with primary ciliary dyskinesia. Eur Respir J $1999 ; 13: 1402-1405$. 
14. Narang I, Ersu R, Wilson NM, Bush A. Nitric oxide in chronic airway inflammation in children: diagnostic use and pathophysiological significance. Thorax. 2002;57:586-589.

15. Wodehouse T, Kharitonov SA, Mackay IS, Barnes PJ, Wilson R, Cole PJ. Nasal nitric oxide measurements for the screening of primary ciliary dyskinesia. Eur Respir J. 2003;21:43-47.

16. Corbelli R, Bringolf-Isler B, Amacher A, Sasse B, Spycher M, Hammer J. Nasal nitric oxide measurements to screen children for primary ciliary dyskinesia. Chest. 2004;126:1054-1059.

17. Mateos-Corral D, Coombs R, Grasemann H, Ratjen F, Dell SD. Diagnostic value of nasal nitric oxide measured with non-velum closure techniques for children with primary ciliary dyskinesia. J Pediatr. 2011;159:420-424.

18. Beydon N, Chambellan A, Alberti C, de Blic J, Clément A, Escudier E, Le Bourgeois M. Technical and practical issues for tidal breathing measurements of nasal nitric oxide in children. Pediatr Pulmonol. 2015;50:1374-1382.

19. Jackson CL, Behan L, Collins SA, Goggin PM, Adam EC, Coles JL, Evans HJ, Harris A, Lackie P, Packham S, et al. Accuracy of diagnostic testing in primary ciliary dyskinesia. Eur Respir J. 2016;47:837-848.

20. Leigh MW, Hazucha MJ, Chawla KK, Baker BR, Shapiro AJ, Brown DE, Lavange LM, Horton BJ, Qaqish B, Carson JL, et al. Standardizing nasal nitric oxide measurement as a test for primary ciliary dyskinesia. Ann Am Thorac Soc. 2013;10:574-81. 
21. Collins SA, Behan L, Harris A, Gove K, Lucas JS. The dangers of widespread nitric oxide screening for primary ciliary dyskinesia. Thorax. 2016;71:560-561.

22. Noone PG, Leigh MW, Sannuti A, Minnix SL, Carson JL, Hazucha M, Zariwala MA, Knowles MR. Primary ciliary dyskinesia: diagnostic and phenotypic features. Am J Respir Crit Care Med. 2004;169:459-467.

23. Santamaria F, De Stefano S, Montella S, Barbarano F, Iacotucci P, Ciccarelli R, Sofia M, Maniscalco M. Nasal nitric oxide assessment in primary ciliary dyskinesia using aspiration, exhalation, and humming. Med Sci Monit Int Med J Exp Clin Res. 2008;14:CR80-85.

24. de Winter-de Groot KM, van der Ent CK. Measurement of nasal nitric oxide: evaluation of six different sampling methods. Eur J Clin Invest. 2009;39:72-77.

25. Piacentini GL, Bodini A, Peroni DG, Sandri M, Brunelli M, Pigozzi R, Boner AL. Nasal nitric oxide levels in healthy pre-school children. Pediatr Allergy Immunol Off Publ Eur Soc Pediatr Allergy Immunol. 2010;21:1139-1145.

26. Boon M, Meyts I, Proesmans M, Vermeulen FL, Jorissen M, De Boeck K. Diagnostic accuracy of nitric oxide measurements to detect primary ciliary dyskinesia. Eur $J$ Clin Invest. 2014;44:477-485.

27. Papon JF, Coste A, Roudot-Thoraval F, Boucherat M, Roger G, Tamalet A, Vojtek AM, Amselem S, Escudier E. A 20-year experience of electron microscopy in the diagnosis of primary ciliary dyskinesia. Eur Respir J. 2010;35:1057-1063.

28. Kouis P, Papatheodorou SI, Yiallouros PK. Diagnostic accuracy of nasal nitric oxide for establishing diagnosis of primary ciliary dyskinesia: a meta-analysis. BMC Pulm Med. 2015;15:153. 
29. Gehring U, Oldenwening M, Brunekreef B, Wieringa MH, Kerkhof M, Smit HA, van der Ent CK, De Jongste JC. The impact of ambient NO on online measurements of exhaled and nasal NO: the PIAMA study. Pediatr Allergy Immunol Off Publ Eur Soc Pediatr Allergy Immunol. 2009;20:665-672.

30. Silkoff PE, Chatkin J, Qian W, Chakravorty S, Gutierrez C, Furlott H, McClean P, Rai S, Zamel N, Haight J. Nasal nitric oxide: a comparison of measurement techniques. Am J Rhinol. 1999;13:169-178. 


\section{TABLES}

Table 1 - Comparisons between proportions of nasal Nitric Oxide measured using different methods in 124 children under 5 years and in 330 children 5 years or older

\begin{tabular}{|l|c|c|c|}
\hline Results are numbers (\%)* & $\begin{array}{c}\text { Tests performed } \\
<5 \text { years }\end{array}$ & $\begin{array}{c}\text { Tests performed } \\
\geq 5 \text { years }\end{array}$ & $P$-value \\
\hline Number of visits & 124 & 330 & \\
\hline nNO-ER measures & $26(21.0)$ & $229(69.4)$ & $<0.0001$ \\
\hline nNO-BH measures & $7(5.6)$ & $174(52.7)$ & $<0.0001$ \\
\hline $\begin{array}{l}\text { Visits with nNO-BH and no nNO- } \\
\text { ER }\end{array}$ & $2(1.6)$ & $49(14.8)$ & $<0.0001$ \\
\hline nNO-TB measures & $121(97.6)$ & $240(72.7)$ & $<0.0001$ \\
\hline Visits with only nNO-TB & $96(77.4)$ & $52(15.7)$ & $<0.0001$ \\
\hline
\end{tabular}

nNO: nasal Nitric Oxide; nNO-ER: NO measurement performed during an expiration against a resistance: nNO-BH: NO measurement performed during a breath holding; nNO-TB: NO measurement performed during tidal breathing

*: percentages of visits in the age group 
Table 2 - Frequency of work-up tests and final diagnosis in 374 study children according to age at inclusion

\begin{tabular}{|l|c|c|}
\hline Results are numbers (\%)* & $\begin{array}{c}\text { Children }<5 \text { years at } \\
\text { inclusion }\end{array}$ & $\begin{array}{c}\text { Children } \geq 5 \text { years at } \\
\text { inclusion }\end{array}$ \\
\hline Children included & 105 & 269 \\
\hline Work-up & $58(55.2)$ & $174(64.7)$ \\
\hline Nasal brushing & $34(32.4)$ & $63 / 268(23.5)$ \\
\hline TEM & $19 / 104(18.3)$ & $48(17.8)$ \\
\hline Genetics studies & \multicolumn{2}{|c|}{} \\
\hline Final diagnosis & $15(14.3)$ & $192(71.4)$ \\
\hline PCD confirmed & $82(78.1)$ & $25(9.3)$ \\
\hline PCD excluded & $6(5.7)$ & $4(1.5)$ \\
\hline Pending cases & $2(1.9)$ & \\
\hline Unconcluded cases & &
\end{tabular}

TEM: transmission electron microscopy on nasal or bronchial biopsy

*: percentages are related to the population defined in the top cell of each column except for genetic studies outcome where missing data were present (the total number of patients with a known outcome is the denominator)

$\dagger$ : Compared to children younger than 5 years of age; $P=0.0002$ 


\section{Figures}

Figure 1 - Age distribution at inclusion in 374 children and for all measurements recorded in the study (454 tests)

Number of children at inclusion (black columns) and at all measurements recorded (grey columns)

Figure 2 - Distribution of 454 tests including one, two or three results of nasal Nitric Oxide according to the methods of measurement used

nNO: nasal Nitric Oxide; nNO-ER: NO measurement performed during expiration against a resistance: $\mathrm{nNO}-\mathrm{BH}$ : $\mathrm{NO}$ measurement performed during breath holding; $\mathrm{nNO}-$ TB: NO measurement performed during tidal breathing

Figure 3 - Age distribution according to methods of nasal Nitric Oxide measurement succeeded by the patients

Tests included: only nasal Nitric Oxide measures using the Tidal Breathing method (black columns); Breath Hold result but no Exhalation against a Resistance result (striped columns); Exhalation against a Resistance result whichever other methods successfully performed or not on the same occasion by the patient (grey columns)

Figure 4 - Bland Altman graphs comparing nasal Nitric Oxide measured using the Expiration against a resistance and alternative methods

Figure 4a - Bland Altman graph comparing the Exhalation against a Resistance with the Breath Hold method in 130 patients 
nNO: nasal Nitric Oxide; ER: Exhalation against a Resistance; BH: Breath Hold

Figure 4b - Bland Altman graph comparing the Exhalation against a Resistance to the Tidal Breathing method in 175 patients

nNO: nasal Nitric Oxide; ER: Exhalation against a Resistance; TB: Tidal Breathing 


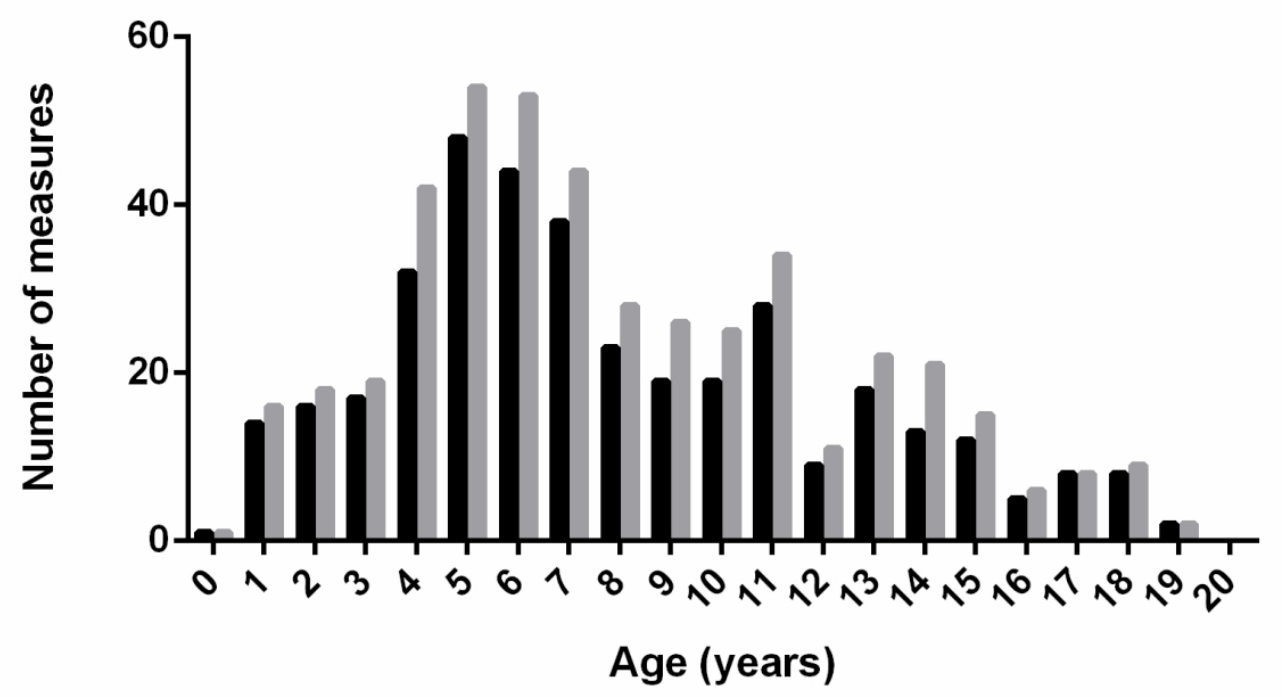

age distribution of tests

$131 \times 76 \mathrm{~mm}(300 \times 300$ DPI $)$ 


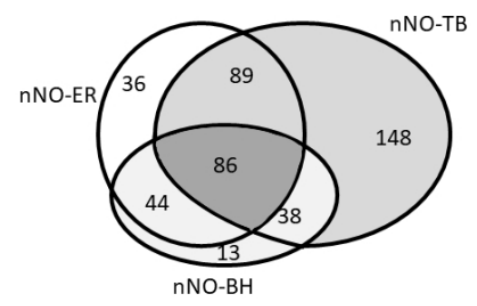

Venn diagram of included nasal No measurements $338 \times 190 \mathrm{~mm}(96 \times 96$ DPI) 


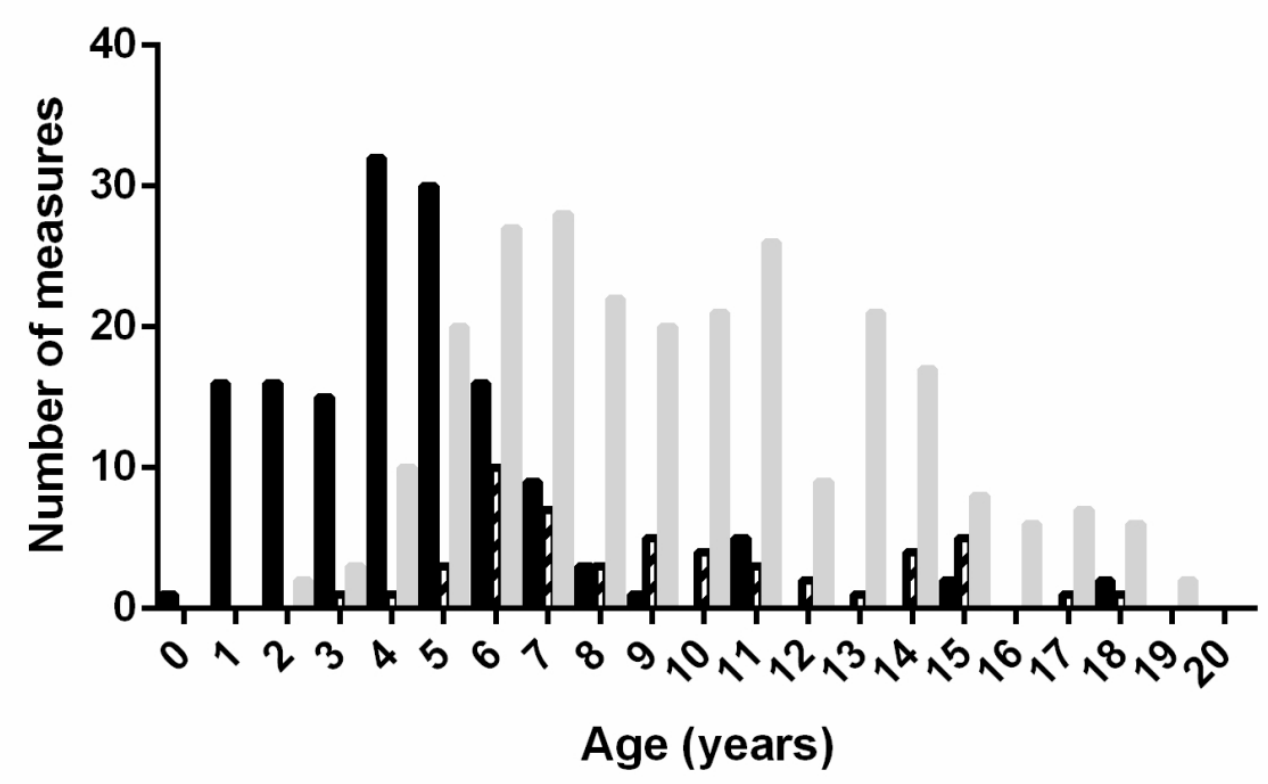

Distribution of age according to methods used to measure nasal NO $117 \times 76 \mathrm{~mm}(300 \times 300 \mathrm{DPI})$ 


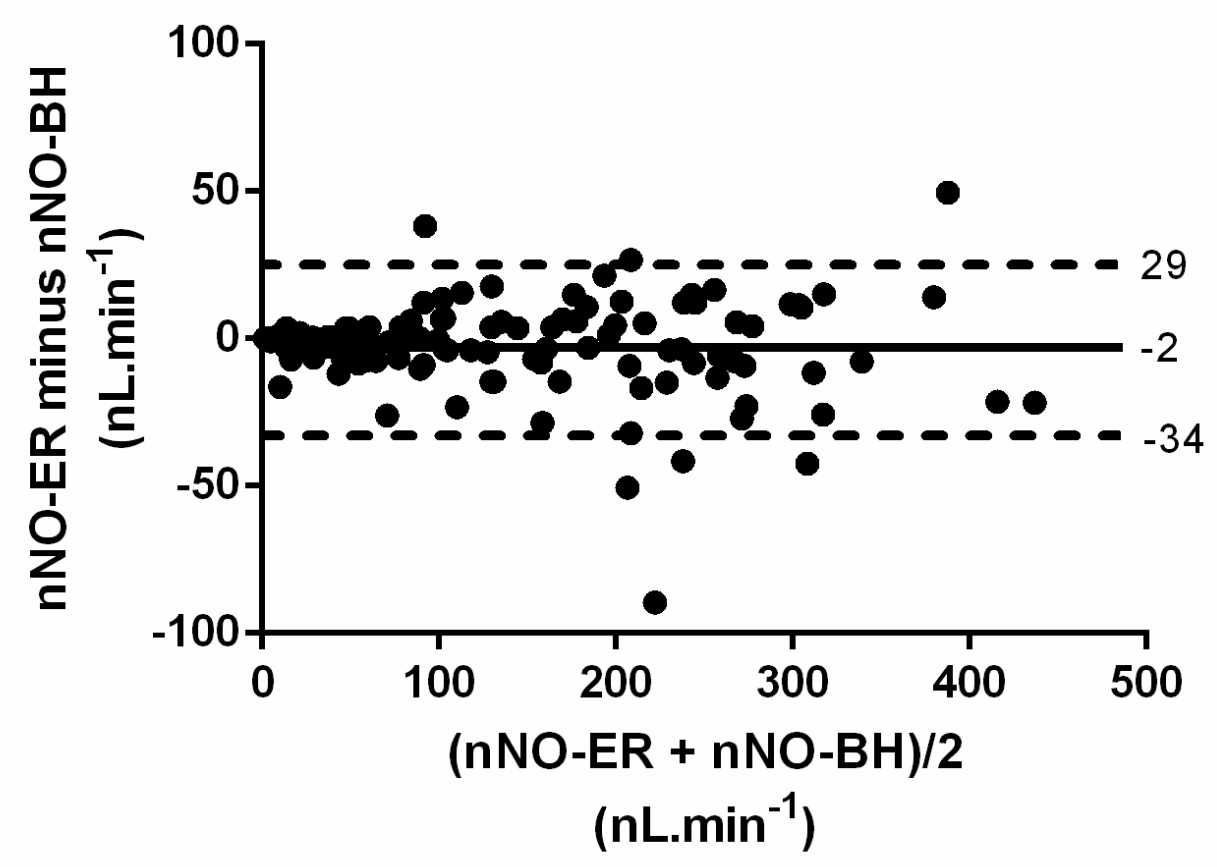

Bland Altman nNO-ER and nNO-BH

$112 \times 79 \mathrm{~mm}(300 \times 300 \mathrm{DPI})$ 


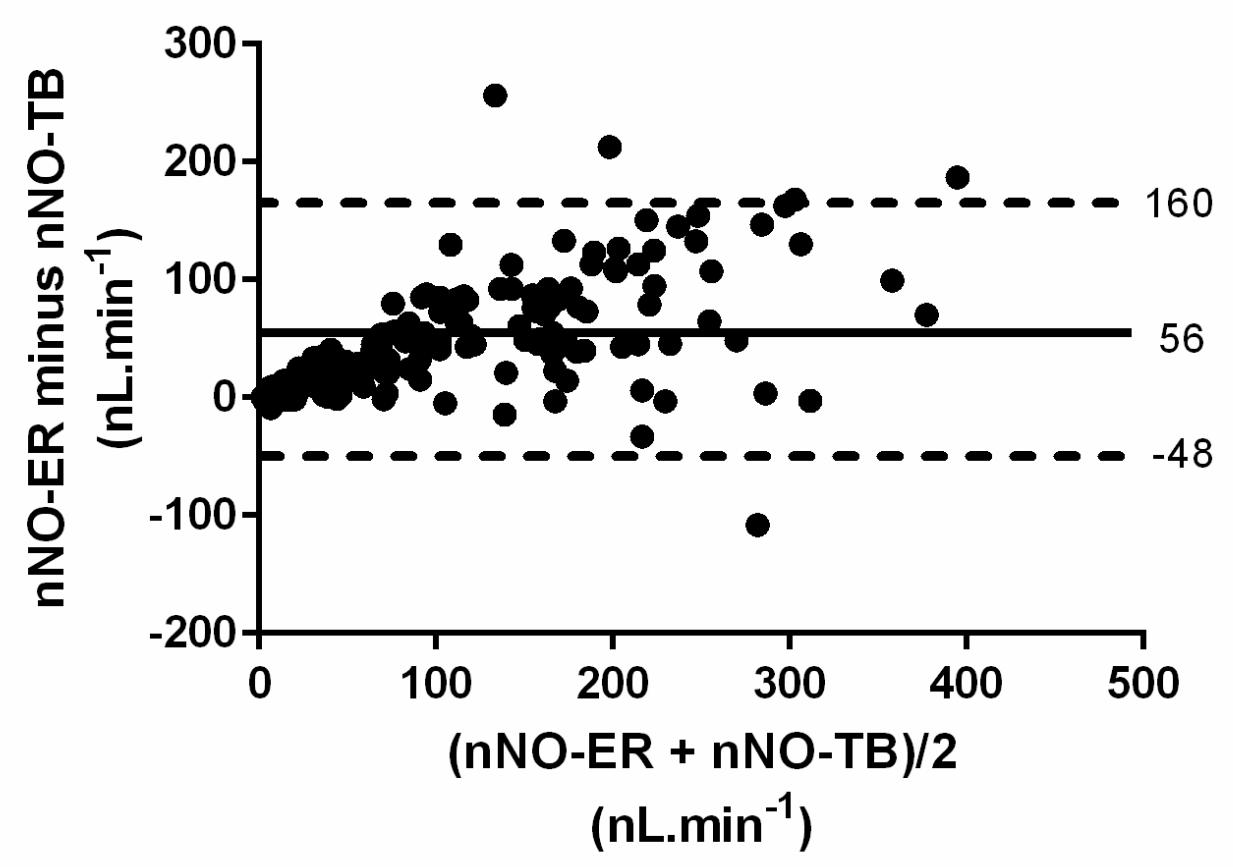

Bland Altman for nNO-ER and nNO-TB

$112 \times 79 \mathrm{~mm}(300 \times 300 \mathrm{DPI})$ 


\section{Breath holding and tidal breathing nasal NO to screen children for Primary Ciliary Dyskinesia}

Nicole Beydon, Aline Tamalet, Estelle Escudier, Marie Legendre, Guillaume Thouvenin

\section{Online Supplementary Material}

\section{Methods}

According to our a Standard Of Procedure (SOP) children under 8 years of age always performed a nNO-TB measurement first while older patients were first tested with nNOER or nNO-BH methods (Figure E1). In case of failure to achieve ER and BH methods or in case of low/borderline results, $\mathrm{nNO}$-TB was measured (in order to confirm low level or to reach for evidence of a blocked nose when $\mathrm{nNO}-\mathrm{TB}$ was higher than $\mathrm{nNO}-\mathrm{ER}$ or nNO$\mathrm{BH})$.

\section{Results}

Among the 413 tests performed in patients 3 years or older, $262(63.4 \%)$ tests included bronchial eNO result. nNO-ER result was available in 208 (79.4\%) cases with successful eNO measurement, whereas it was available in only $44(29.3 \%)$ cases among the 150 tests without eNO result $(P<0.0001)$. The likelihood ratio for a patient to succeed at nNO-ER measure when eNO was possible was 2.4. As expected, patients without eNO were significantly younger than those able to perform a correct eNO measurement $(7.4$ [4.2;6.7] versus $9.9[7.0 ; 12.9]$ years; $P<0.0001)$. It is to be noted that eNO values measured in PCD patients were lower than those obtained in patients in whom PCD was excluded (median [Q1;Q3] 4.1 [2.7;6.4] versus 8.0 [5.9;13.7]; P $<0.0001)$. 
The dataset encompassed repeated nNO measurements in 57 (15.2\%) children, consisting in most of the cases in 2 measurements per child (41 cases, $71.9 \%$ ). Measures of $n N O$ were repeated at least twice using the same method in $26(12.6 \%), 13(8.7 \%)$ and 44 (14.9\%) children for ER, BH or TB methods, respectively. The medians [Q1;Q3] delay between the two measurements were $12[6 ; 18.2], 11[2.5 ; 21]$, and $12.5[5.2 ; 21.5]$ months for ER, BH and TB methods, respectively, and medians [Q1;Q3] of differences (second minus first measurement) were $11.3[-0.6 ; 77.9], 8.6[-5.3 ; 62.0]$, and $10.0[-2.3$ ; 31.6] nL.min ${ }^{-1}$, respectively (Figures E4). The proportion of children with repeated measures was similar between children first tested under 5 years or patients seen at first at 5 years or older ( $20 \%$ versus $13.4 \%, P=0.15$ ) (Table 1$)$. Among the 21 children seen at first before 5 years and with repeated measures, 9 children had at least one measure after 5 years of which 5 had only one measure before 5 years of age.

Sensitivities and specificities were calculated for the three methods, using a maximum of one result per method for each patient. In case of more than one result per method in a child, we used the highest value obtained with ambient $\mathrm{NO} \leq 20 \mathrm{ppb}$.

Low sensitivity of TB method was explained by three false negative tests (values higher than the threshold in PCD children) because of a RSPH1 or CCDC103 mutation in two children, or a child with Kartagener syndrome and pending genetic results. Age at measurement, $\mathrm{nNO}-\mathrm{TB}$ and ambient $\mathrm{NO}$ values in these three children were, respectively: 3.5 years, $164 \mathrm{ppb}\left(54 \mathrm{~nL} \cdot \mathrm{min}^{-1}\right)$ and $8.7 \mathrm{ppb} ; 3.9$ years, $211 \mathrm{ppb}\left(70 \mathrm{~nL} \cdot \mathrm{min}^{-1}\right)$ and $0 \mathrm{ppb}$; and 4.9 years, $319 \mathrm{ppb}\left(96 \mathrm{~nL} \cdot \mathrm{min}^{-1}\right)$ and $1.9 \mathrm{ppb}$.

In 230 children (47/230 PCD) younger than 12 years or in 190 children (37/190 PCD) younger than 8 years ROC analyses did not show different thresholds for TB method 
compared to the threshold we previously established ${ }^{\mathrm{E} 1}$ and used in this study (Table E2). However, specificity appeared slightly better compared to that of children younger than 5 years.

In children less than 5 years of age with PCD diagnosis excluded, nNO-TB was equal to or higher than $40 \mathrm{~nL} \cdot \mathrm{min}^{-1}$ in $72 / 86(83.7 \%)$ cases, of whom 40 were less than 4 years. In the remaining 11 measurements performed under 4 years of age in children without PCD, nNO-TB was higher than the threshold calculated according to age (Table E1) in only one measurement.

Median [Q1;Q3](range) of ambient NO (NOamb) measured before 449 (99\%) tests was $6.4[1.9 ; 19](0-126) \mathrm{ppb}$ and superior to $20 \mathrm{ppb}$ in 103 cases (22.9\%) (Figure E3). The effect of NOamb was assessed by noting whether after subtracting it to the nNO measure, nNO value remained the same side of the threshold or not. Correcting NO for NOamb would have changed the interpretation of $\mathrm{nNO}$ in 16 tests performed in 15 children of which 12 were 9 years or younger at the time of measurement (Table E4). In three ER measurements (1.2\% of ER measurements) and in three other cases of BH measurements (1.7\% of $\mathrm{BH}$ measurements) $\mathrm{nNO}$ would decrease from above to under the discriminant threshold; whereas it would happen in 12 cases for TB measurements $(3.3 \%$ of TB measurements, two cases with concomitant decrease of nNO-ER under the threshold, and one case with concomitant decrease of nNO-BH under the threshold). In seven cases (43.7\%), ambient NO was $20 \mathrm{ppb}$ or less, which means that the $\mathrm{nNO}$ measurements were close to the threshold. In five cases where nNO-VT had been evaluated on another occasion, three children showed a subsequent nNO-VT value above the threshold and two lower than the threshold. 


\section{Discussion}

Corbelli and colleagues reported that among 58 children able to perform nNO-BH, four $(6.9 \%)$ were unable to correctly achieve eNO measurement ${ }^{\mathrm{E} 2}$ which requires the same respiratory maneuver than the ER measurement. This is close to the $14.8 \%$ of our study children who could perform nNO-BH but not nNO-ER, representing a small but true population for which nNO-BH was useful. Therefore, the advantage of $\mathrm{BH}$ method would not be to allow a decrease in the age of children performing nNO measurement but to offer an alternative method for school aged or older patients unable to perform nNO-ER.

\section{References}

E1. Beydon N, Chambellan A, Alberti C, de Blic J, Clément A, Escudier E, Le Bourgeois M. Technical and practical issues for tidal breathing measurements of nasal nitric oxide in children. Pediatr Pulmonol. 2015;50:1374-1382.

E2. Corbelli R, Bringolf-Isler B, Amacher A, Sasse B, Spycher M, Hammer J. Nasal nitric oxide measurements to screen children for primary ciliary dyskinesia. Chest. 2004;126:1054-1059. 


\section{E Tables}

Tables E1 - Thresholds of nasal Nitric Oxide used for the tidal breathing method in children under 4 years of age

\begin{tabular}{|c|c|}
\hline Age (years) & Threshold (nL.min ${ }^{-1}$ ) \\
\hline 0.1 & 9 \\
\hline 0.2 & 11 \\
\hline 0.3 & 13 \\
\hline 0.3 & 16 \\
\hline 0.4 & 18 \\
\hline 0.5 & 21 \\
\hline 0.6 & 23 \\
\hline 0.7 & 26 \\
\hline 0.8 & 29 \\
\hline 0.8 & 31 \\
\hline 0.9 & 33 \\
\hline 1.0 & 34 \\
\hline 1.0 to 1.5 & 34.5 \\
\hline 1.5 to 2.0 & 35 \\
\hline 2.0 to 2.5 & 36 \\
\hline 2.5 to 3.0 & 37 \\
\hline 3.0 to 3.5 & 38 \\
\hline 3.5 to 4 & 39 \\
\hline$\geq 4$ & 40 \\
\hline
\end{tabular}

The Tidal Breathing value was the mean of 5 peaks during regular breathing. Thresholds are the Lower limit of normal from birth to 1 year of age, the previously published threshold for children 4 years or older ${ }^{\mathrm{E} 1}$ and a smooth connection between 1 and 4 years of age. 
Table E2 - Thresholds of nasal Nitric Oxide measured using tidal breathing method in 230 children younger than 12 years and in 190 children younger than 8 years

\begin{tabular}{|l|c|c|c|c|c|c|}
\hline & $\begin{array}{c}\text { PCD } \\
\text { confirmed }\end{array}$ & $\begin{array}{c}\text { PCD } \\
\text { excluded }\end{array}$ & $\begin{array}{c}\text { AUC } \\
(95 \% \mathrm{CI})\end{array}$ & $\begin{array}{c}\text { Sensitivity } \\
(\%)\end{array}$ & $\begin{array}{c}\text { Specificity } \\
(\%)\end{array}$ & $\begin{array}{c}\text { Threshold } \\
\left(\mathrm{nL} \cdot \mathrm{min}^{-1}\right)\end{array}$ \\
\hline $\begin{array}{l}\text { Children } \\
<12 \text { years }\end{array}$ & 47 & 183 & 0.88 & 76.6 & 89.1 & 40.8 \\
\hline $\begin{array}{l}\text { Children } \\
<8 \text { years }\end{array}$ & 37 & 153 & 0.88 & 78.4 & 90.9 & 40.8 \\
& & $(0.80 ; 0.95)$ & & & \\
\hline
\end{tabular}

PCD: Primary Ciliary Dyskinesia; AUC: Area Under the Curve; CI: Confidence Interval 
Table E3 - Frequency of work-up tests, final diagnosis and Tidal Breathing nasal Nitric Oxide results in children younger than 5 years at inclusion according to the method of nasal Nitric Oxide measurement they succeeded

\begin{tabular}{|c|c|c|}
\hline $\begin{array}{l}\text { Results are numbers }(\%)^{*} \\
\text { nNO-TB median }[\mathrm{Q} 1 ; \mathrm{Q} 3](\mathrm{ppb})^{\#}\end{array}$ & $\begin{array}{c}\text { Children }<5 \text { years with } \\
\text { nNO-ER }\end{array}$ & $\begin{array}{c}\text { Children }<5 \text { years with } \\
\text { only nNO-TB }\end{array}$ \\
\hline Children included & 24 & 79 \\
\hline nNO-TB & $\mathrm{n}=23,174[49 ; 281]$ & $214[88 ; 340]$ \\
\hline \multicolumn{3}{|l|}{ Work-up } \\
\hline Nasal brushing & $12(50.0)$ & $44(55.7)$ \\
\hline nNO-TB & $145[33 ; 220]$ & $155[57 ; 306]$ \\
\hline TEM & $8(33.3)$ & $26(32.9)$ \\
\hline nNO-TB & $56[33 ; 199]$ & $76[42 ; 198]$ \\
\hline Genetics study & $4(16.7)$ & $15 / 78(19.2)$ \\
\hline nNO-TB & $28 ; 29 ; 174 ; 34$ & $42[26 ; 74]$ \\
\hline \multicolumn{3}{|l|}{ Final diagnosis } \\
\hline PCD confirmed & $3(12.5)$ & $12(15.2)$ \\
\hline nNO-TB & $28 ; 34 ; 45$ & $42[25 ; 65]$ \\
\hline PCD excluded & $19(79.2)$ & $61(77.2)$ \\
\hline nNO-TB & $\mathrm{n}=18,228[105 ; 395]$ & $275[159 ; 382]$ \\
\hline Pending cases & $2(8.3)$ & $4(5.1)$ \\
\hline nNO-TB & $29 ; 174$ & $25 ; 254 ; 114 ; 86$ \\
\hline Unconcluded cases & $0(-)$ & $2(2.5)$ \\
\hline nNO-TB & & $33 ; 56$ \\
\hline
\end{tabular}

nNO-TB: nasal Nitric Oxide measurement performed during tidal breathing; nNO-ER: nasal Nitric Oxide measurement performed during expiration against a resistance; TEM: transmission electron microscopy on nasal or bronchial biopsy 
*: percentages are related to the population defined in the top cell of each column except for genetic study outcome in children with only nNO-TB result because of missing data (the total number of patients with a known outcome is the denominator)

\#: nNO-TB value at inclusion for the children of the cell. The number of measurements is equal to the number of children displayed in the cell, or otherwise specified left of the nNO-TB values. Series of 4 children or less are given in extenso 
Table E4 - Values of nasal NO changing from above to under the threshold after subtracting ambient NO in 16 tests performed in 15 children

\begin{tabular}{|c|c|c|c|c|c|c|c|c|}
\hline Patients & AGE & NOamb & $\begin{array}{l}\text { nNO- } \\
\text { ER }\end{array}$ & $\begin{array}{l}\text { nNO-ER } \\
\text { minus } \\
\text { NOamb }\end{array}$ & nNO-BH & $\begin{array}{l}\text { nNO-BH } \\
\text { minus } \\
\text { NOamb }\end{array}$ & nNO-TB & $\begin{array}{l}\text { nNO-TB } \\
\text { minus } \\
\text { NOamb }\end{array}$ \\
\hline $1 \mathrm{ppb}$ & 6.8 & 17.3 & & & 276 & 258.7 & & \\
\hline $2 \mathrm{ppb}$ & 14.2 & 70 & 349 & 279 & 327 & 257 & 162 & 92 \\
\hline $3 \mathrm{ppb}$ & 14.7 & 13 & 255.2 & 242.2 & 286.2 & 273.2 & 133.6 & 120.6 \\
\hline $4 \mathrm{ppb}$ & 5.7 & 10 & 190 & 180 & 178 & 168 & 139 & 129 \\
\hline $5 \mathrm{ppb}$ & 5.7 & 45 & 142 & 97 & 140 & 95 & 136 & 91 \\
\hline $5 \mathrm{ppb}$ & 5.8 & 0.7 & & & & & 155.5 & 154.8 \\
\hline $6 \mathrm{ppb}$ & 6.8 & 17 & 290 & 273 & 270 & 253 & 139 & 122 \\
\hline $7 \mathrm{ppb}$ & 0.3 & 42 & & & & & 68 & 26 \\
\hline $7 \mathrm{ppb}$ & 1.0 & 5 & & & & & 121.4 & 116.4 \\
\hline $7 \mathrm{ppb}$ & 3.3 & 5 & & & & & 31.48 & 26.5 \\
\hline $7 \mathrm{ppb}$ & 3.9 & 0 & & & & & 211 & 211 \\
\hline $8 \mathrm{ppb}$ & 8.1 & 78 & & & 224 & 146 & 205.3 & 127.3 \\
\hline
\end{tabular}




\begin{tabular}{|c|c|c|c|c|c|c|c|c|}
\hline $8 p p b$ & 8.9 & 17 & 154 & 137 & 143 & 126 & 113.8 & 96.8 \\
\hline $9 \mathrm{ppb}$ & 6.2 & 42 & 132 & 90 & & & 135 & 93 \\
\hline $\mathbf{1 0} \mathrm{ppb}$ & 5.9 & 18 & 289 & 271 & 319 & 301 & 187 & 169 \\
\hline $11 \mathrm{ppb}$ & 3.6 & 10.5 & & & & & 134 & 123.5 \\
\hline $11 \mathrm{ppb}$ & 4.6 & 20 & & & & & 383 & 363 \\
\hline $12 \mathrm{ppb}$ & 3.1 & 30 & & & & & 125.6 & 95.6 \\
\hline $12 \mathrm{ppb}$ & 4.1 & 25 & & & & & 154.7 & 129.7 \\
\hline $13 \mathrm{ppb}$ & 13.4 & 20 & 205 & 185 & & & 149.8 & 129.8 \\
\hline $\begin{array}{l}13 \mathrm{ppb} \\
\mathrm{nL} \cdot \mathrm{min}^{-1}\end{array}$ & 13.9 & 24 & 868.8 & 844.8 & & & & \\
\hline $14 \mathrm{ppb}$ & 9.1 & 40 & & & 252 & 212 & 143 & 103 \\
\hline $15 \mathrm{ppb}$ & 6.1 & 6.2 & 277 & 270.8 & & & 208 & 201.8 \\
\hline
\end{tabular}

NOamb: ambient NO; nNO: nasal nitric oxide; ER: expiration against a resistance; $\mathrm{BH}$ breath hold; TB Tidal Breathing

Values in bold are those who changed from above to under the threshold (274 ppb for ER or $\mathrm{BH}$ methods, and $133 \mathrm{ppb}$ for $\mathrm{TB}$ method) values in italic are those recorded in the same patient on another occasion (before or after). Patients $5,7,8,11,12,13$ were tested at least twice. 


\section{E-Figures}

Figure E1 - Standard Of Procedure used since 2015 at Armand Trousseau Hospital ER: Expiration against resistance method; $\mathrm{BH}$ breath hold method; TB: Tidal Breathing method

Figure E2 - Years of measurement distribution of the 454 files included in the study

Figure E3 - Distribution of ambient NO values measured before 449 tests

Figures 4 - Difference between two successive measurements of nasal nitric Oxide obtained using the same method according to the delay between the measures

Figure 4a - Difference between two successive measurements of nasal nitric Oxide obtained using the Tidal Breathing method according to the delay between the two measures in 44 children

nNO-TB: nasal Nitric Oxide measured using the Tidal Breathing method

Figure 4b - Difference between two successive measurements of nasal nitric Oxide obtained using the Expiration against a Resistance method according to the delay between the two measures in 26 children

nNO-ER: nasal Nitric Oxide measured using the Expiration against a Resistance method 


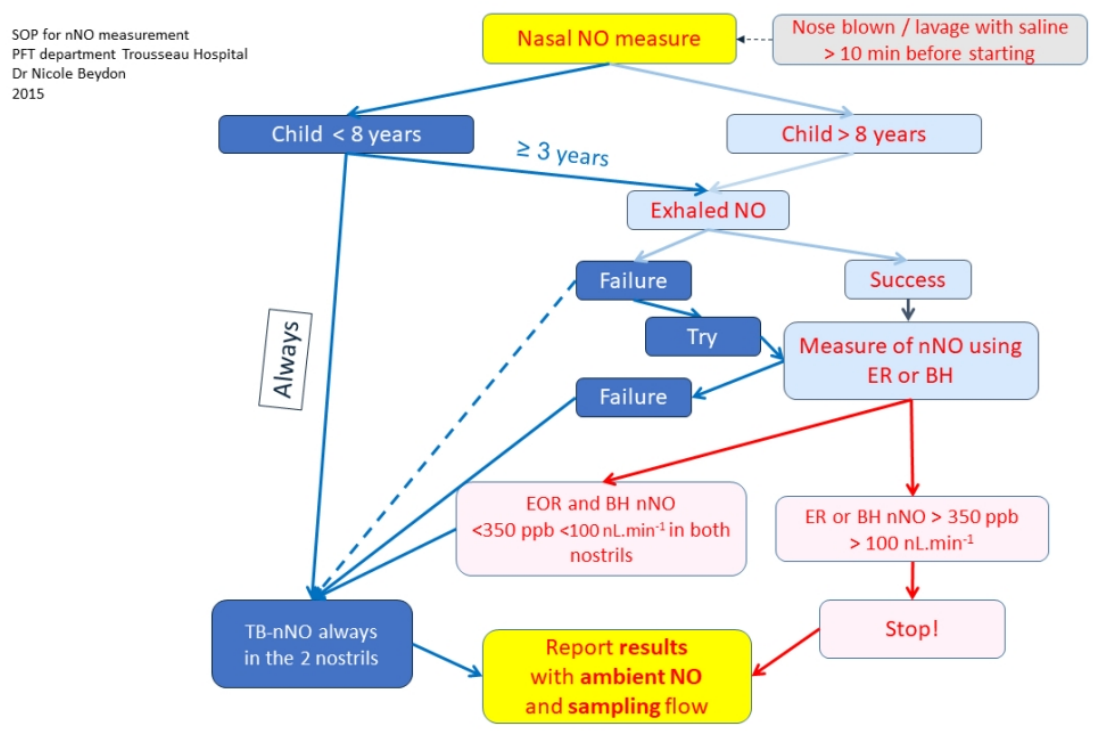

$338 \times 190 \mathrm{~mm}(96 \times 96$ DPI) 


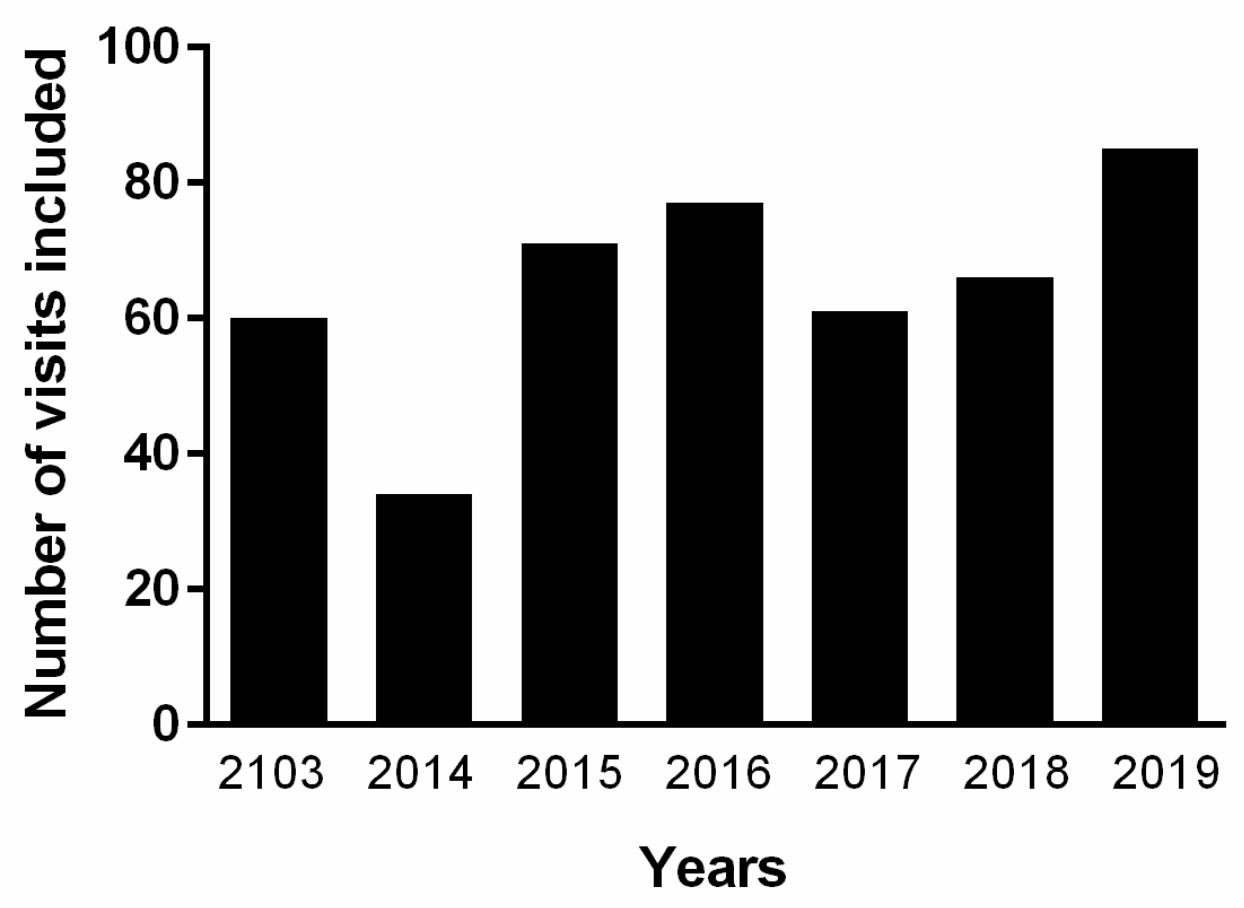

$97 \times 74 \mathrm{~mm}(300 \times 300$ DPI $)$ 


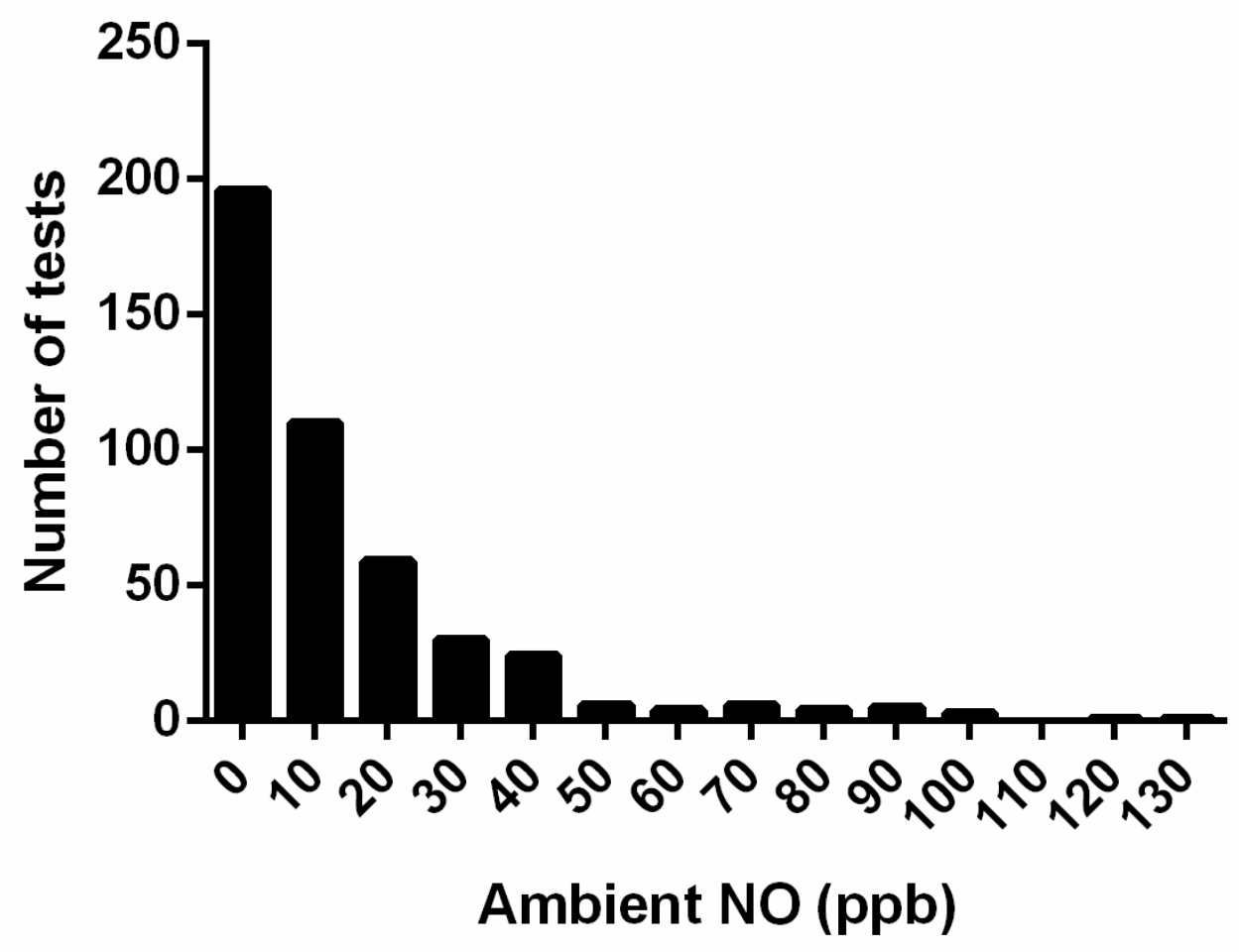

$96 \times 77 \mathrm{~mm}(300 \times 300$ DPI $)$ 


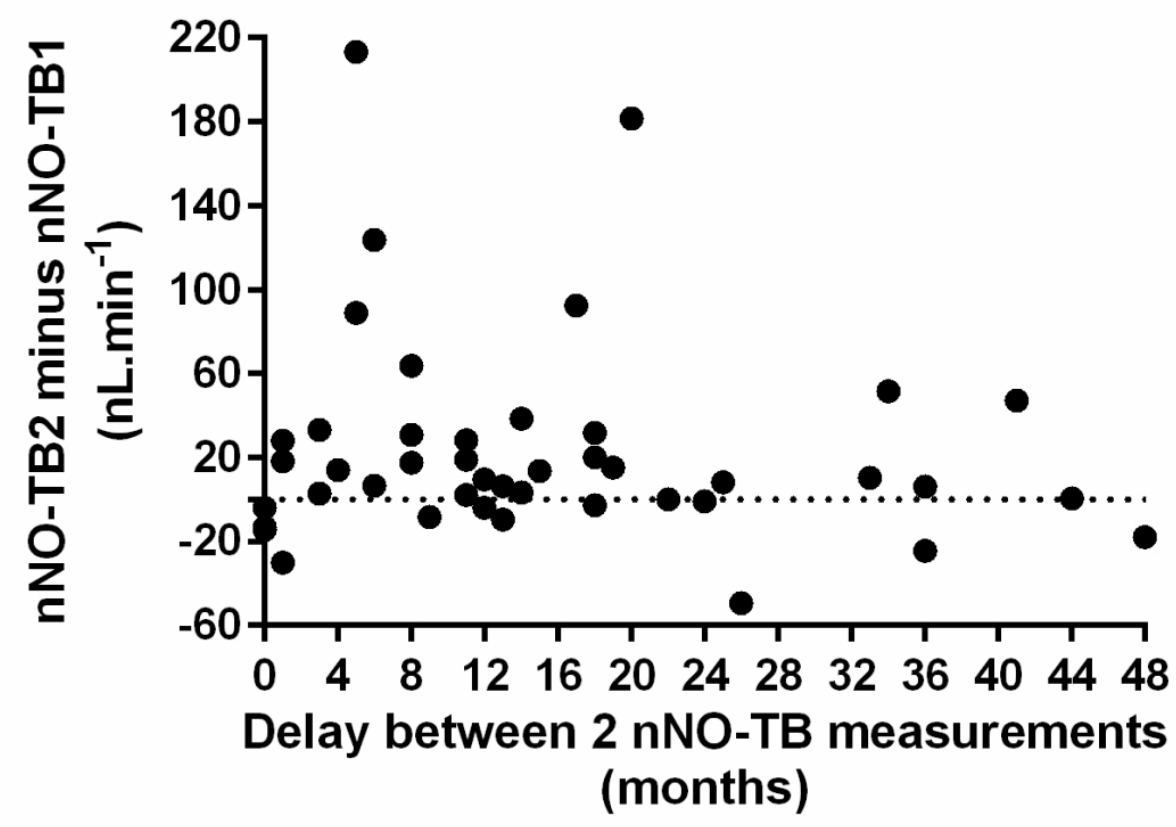

$112 \times 77 \mathrm{~mm}(300 \times 300$ DPI $)$ 


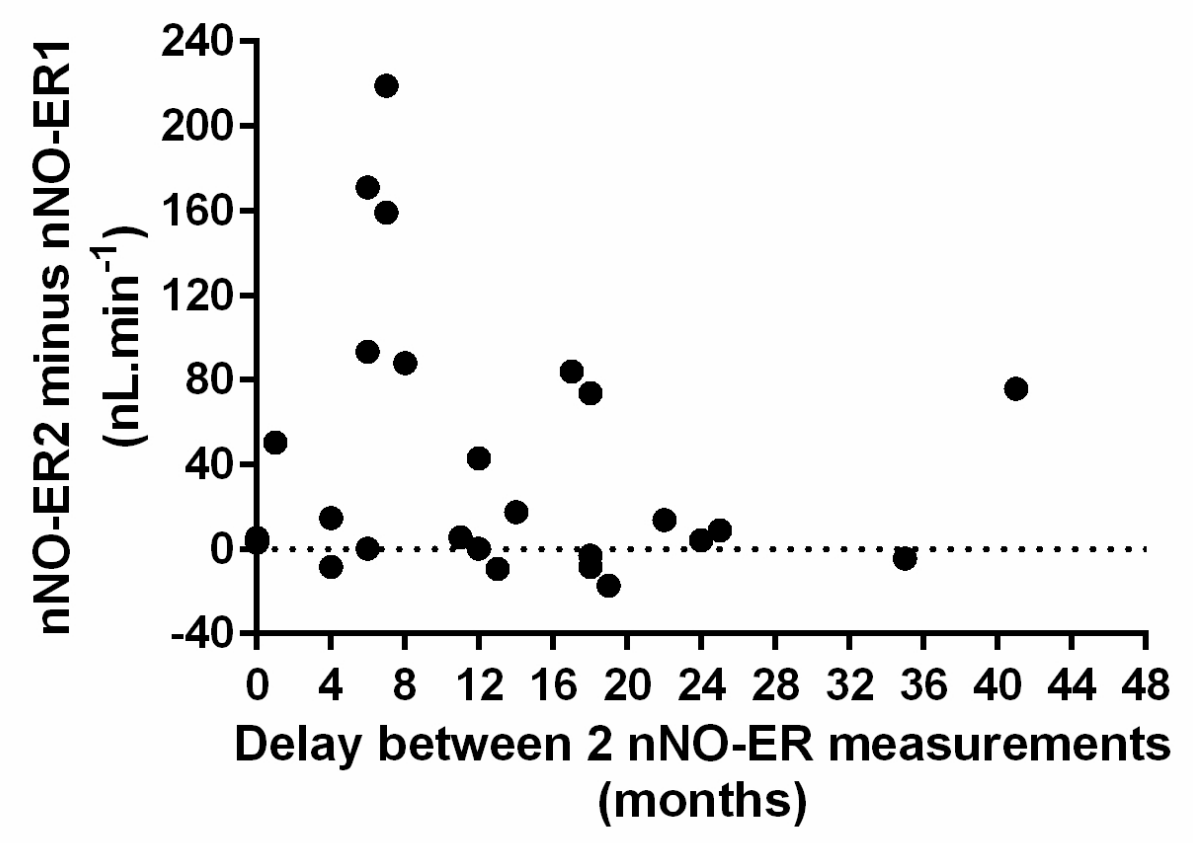

$111 \times 78 \mathrm{~mm}(300 \times 300$ DPI $)$ 